\section{Commentary: A century of giant paraesophageal hernia (GPEH) repair: A century of controversy!}

\author{
Saurav Adhikari, MD, and Siva Raja, MD, PhD, FACS
}

Giant paraesophageal hernias (GPEHs) can range from an asymptomatic, incidentally detected paraesophageal hernias to an emergent gastric volvulus with concern for ischemia. ${ }^{1}$ For many decades, the fear of gastric volvulus and its associated risk of mortality (29\%), noted in the 1967 work by Drs Skinner and Belsey, has driven the paradigm of urgent repair of GPEH. ${ }^{2}$ We now know that there are many patients with GPEH who are incidentally diagnosed and have minimal symptoms. Given that elective repair is associated low mortality and morbidity and contrasting it with the low risk of obstructive and gangrenous complications per year, the lifetime risk of developing complications needs to be taken into account before considering repair. ${ }^{3}$

In their article by Bhargava and Rafael, ${ }^{4}$ the authors identify knowledge gaps and describe a systematic approach to evaluation, management, and follow-up of patients with GPEH. They note that despite the long history of treating GPEH, there is still no consensus about its definition. Interestingly, we encountered the same problem 20 years ago in writing our manuscript and came up with the similar solution of arbitrarily deciding on $33 \%$ of the stomach in the chest as the definition of GPEH. ${ }^{5}$ Their approach of thoughtful use of surgical correction versus observation, the use of temporizing measures such as endoscopic reduction, and feeding access are sound. Most surgeons in the modern era would not subscribe to a need for the proposed

\footnotetext{
From the Department of Thoracic and Cardiovascular Surgery, Heart and Vascular Institute, Cleveland Clinic, Cleveland, Ohio.

Disclosures: The authors reported no conflicts of interest.

The Journal policy requires editors and reviewers to disclose conflicts of interest and to decline handling or reviewing manuscripts for which they may have a conflict of interest. The editors and reviewers of this article have no conflicts of interest.

Received for publication July 1, 2020; revisions received July 1, 2020; accepted for publication July 2, 2020; available ahead of print July 9, 2020.

Address for reprints: Siva Raja, MD, PhD, FACS, Department of Thoracic and Cardiovascular Surgery, Heart and Vascular Institute, Cleveland Clinic Foundation, J4-1, 9500 Euclid Ave, Cleveland, OH 44195 (E-mail: rajas@ccf.org).

JTCVS Techniques 2020;3:373-4

2666-2507

Copyright ( $\subset 2020$ The Authors. Published by Elsevier Inc. on behalf of The American Association for Thoracic Surgery. This is an open access article under the CC BY-NCND license (http://creativecommons.org/licenses/by-nc-nd/4.0/).

https://doi.org/10.1016/j.xjtc.2020.07.004
}

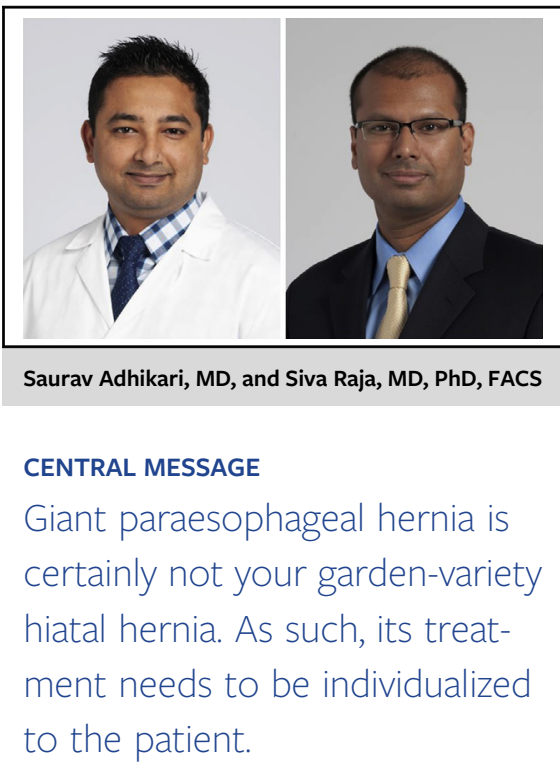

legacy procedure of decompressive pharyngostomy for long-term decompression. Lastly, the authors provide an expert review on the surgical principles of repair and a much-needed separate strategy for the treatment of GPEH in patients with morbid obesity.

The 2 controversial elements highlighted in this paper are the need for esophageal lengthening and the use of mesh. ${ }^{4}$ There have been few, if any, long-term series with results as good as the one by Maziak and colleagues ${ }^{6}$ when a Collis gastroplasty was liberally used along with a fundoplication. Some surgeons question the existence of the entity of a shortened esophagus entirely. However, the perceived need for open surgery for an esophageal-lengthening procedure has been a barrier for many minimally invasive surgeons to consider it. Admittedly, an esophageal-lengthening procedure adds time, marginally increases the risk of a leak, and can be challenging to do laparoscopically, but numerous techniques have now been described to accomplish this minimally invasively. As such, these techniques to relieve tension on the repair can be vital in reducing the high recurrence rate of these challenging cases.

The use of mesh during a GPEH repair remains a subject of much debate. Although there have been some scenarios that do need mesh, the routine use of mesh is probably not prudent. Given that the underlying cause of the GPEH is a weakness in the diaphragm, the need for redo hernia surgery is a reality for many. The use of mesh increases the challenges for redo hernia surgery without a substantive decrease in recurrence rates. ${ }^{7}$ The one tenet of repair that most of us can agree on is that a prosthetic mesh adjacent to the esophagus and the stomach is ill advised. 
As we have become adept at repairing GPEH, we are also getting better at redoing it! GPEHs are challenging to repair, and their subsequent management needs to be individualized. Its complexities do mandate that it be done by experienced physicians and not be treated as your garden-variety type I sliding hiatal hernia.

\section{References}

1. Choi S, Tang A, Murthy S, Raja S. Preoperative evaluation and clinical decision making for giant paraesophageal hernias: who gets an operation? Thorac Surg Clin. 2019;29:415-9.

2. Skinner DB, Belsey RH. Surgical management of esophageal reflux and hiatus hernia. Long-term results with 1030 patients. J Thorac Cardiovasc Surg. 1967; 53:33-54.
3. Paul S, Mirza FM, Nasar A, Port JL, Lee PC, Stiles BM, et al. Prevalence, outcomes, and a risk-benefit analysis of diaphragmatic hernia admissions: an examination of the National Inpatient Sample database. J Thorac Cardiovasc Surg. 2011;142:747-54.

4. Bhargava A, Rafael A. Giant paraesophageal hernia: what do we really know? J Thorac Cardiovasc Surg Tech. 2020;3:367-72.

5. Luketich JD, Raja S, Fernando HC, Campbell W, Christie NA, Buenaventura PO, et al. Laparoscopic repair of giant paraesophageal hernia: 100 consecutive cases. Ann Surg. 2000;232:608-18.

6. Maziak DE, Todd TR, Pearson FG. Massive hiatus hernia: evaluation and surgical management. J Thorac Cardiovasc Surg. 1998;115:53-60; discussion 61-52.

7. Oelschlager BK, Pellegrini CA, Hunter JG, Brunt ML, Soper NJ, Sheppard BC, et al. Biologic prosthesis to prevent recurrence after laparoscopic paraesophageal hernia repair: long-term follow-up from a multicenter, prospective, randomized trial. J Am Coll Surg. 2011;213:461-8. 